\title{
LIBERTAD DE TESTAR, DERECHOS LEGITIMARIOS Y SOLIDARIDAD FAMILIAR
}

\section{TESTAMENTARY FREEDOM, FORCED HEIRSHIP AND FAMILY SOLIDARITY}

Susana Espada Mallorquín*

\section{RESUMEN}

Se han producido cambios sociológicos en la estructura familiar y en los roles de género, en las relaciones personales y afectivas entre padres e hijos, existe una mayor preocupación por la protección de las personas dependientes o descendientes incapacitados. También existen cambios de carácter económico, desde la configuración del patrimonio y el fundamento de su transmisibilidad a determinados familiares, en la protección de las empresas familiares. Todos estos cambios deberían motivar reformas sucesorias profundas, salvo que queramos ser testigos pasivos de la obsolescencia del derecho sucesorio. Se propone como punto de partida repensar el fundamento de las asignaciones forzosas desde la solidaridad intergeneracional.

Palabras clave: libertad de testar; asignaciones forzosas; solidaridad intergeneracional.

* Doctora en Derecho por la Universidad Autónoma de Madrid. Profesora asociada de la Facultad de Derecho de la Universidad Adolfo Ibáñez. Dirección postal: Avenida Diagonal Las Torres 2640, Peñalolén, Región Metropolitana. Correo electrónico: susana. espada@uai.cl

Agradezco los interesantes comentarios que los profesores de la Facultad de Derecho de la Universidad Adolfo Ibáñez llevaron a cabo en la exposición que sobre el presente artículo se realizó en nuestro Seminario. De igual forma el presente artículo se enmarca como contribución de la autora como investigadora del proyecto: "Hacia una revisión del principio de solidaridad familiar: Análisis de su alcance y límites actuales y futuros". PID2019104226GB-I00/AEI/10.13039/501100011033 (Ministerio de Ciencia e Innovación/ Agencia Estatal de Investigación). IP: Pilar Benavente Moreda y Alma M. Rodríguez Guitián, España.

Recepción: 2020-08-30; aceptación: 2021-01-07. 


\begin{abstract}
There have been sociological changes in the family structure and gender roles, in personal and affective relationships between parents and children, there is greater concern for the protection of dependent persons or incapacitated descendants. There are also changes of an economic nature, from the configuration of assets and the basis for their transferability to certain family members, to the protection of family businesses. All these changes should motivate profound succession reforms, unless we want to be passive witnesses of the obsolescence of inheritance law. It is proposed as a starting point to rethink the foundation of the forced heirship from the intergenerational solidarity.
\end{abstract}

Keywords: Testamentary freedom, Forced heirship, Intergenerational solidarity.

\title{
INTRODUCCIÓN
}

Es posible afirmar que existe una vinculación esencial entre el derecho de familia y el derecho de sucesiones. Así lo han destacado varios autores, entre ellos José María Miquel que señala:

“[...] Familia y propiedad configuran la realidad social de una manera tan intensa que suele influir en la determinación de lo que se considera la voluntad del testador"

y, por lo tanto,

"[...] una decisión en favor de la libertad de testar y en contra de la legítima no corresponde al intérprete, sino que es una decisión de política legislativa que en un Estado de derecho le corresponde al poder legislativo. Si las convicciones de los intérpretes sobre familia y propiedad influyen indebidamente a la hora de determinar la voluntad del testador, los principios constitucionales y del Código civil configuran de manera ineludiblemente vinculante el marco del que esa voluntad ha de ser reconocida [...]"1.

Las últimas reformas de las instituciones familiares se han caracterizado por una mayor relevancia de la autonomía de la voluntad en el desarrollo

${ }^{1}$ Miduel (2002), pp. 153-154. 
de las relaciones de familia. Dicha autonomía de la voluntad siempre resultó esencial en el ámbito sucesorio a través de la libertad de testar.

El presente artículo propone reflexionar e intentar encontrar el difícil equilibrio entre las normas imperativas en los sistemas sucesorios que identifican la legítima como una atribución forzosa con las normas dispositivas que imperan en la defensa de la libertad de testar. Para ello es preciso partir identificando cuáles son en la actualidad las principales variables sociológicas, económicas y sociales relevantes en la discusión de la atribución de las asignaciones mortis causa. Posteriormente, se analizarán críticamente las diversas opciones legislativas y doctrinales existentes en esta materia y su fundamento, y, por último, se propondrá un nuevo enfoque interpretativo basado en la reflexión sobre el fundamento de la atribución sucesoria, que permita contribuir a encontrar el difícil equilibrio aludido.

Por lo tanto, la hipótesis de partida del presente trabajo es que se considera que el equilibrio entre autonomía de la voluntad y protección de la asignación forzosa es posible y se encuentra en legitimar solo la atribución de la asignación sucesoria legal (intestada y legitimaria) en aquellos casos en los que se verifique la existencia de una solidaridad familiar efectiva en vida del causante.

\section{LA HERENCIA Y LAS RELACIONES FAMILIARES}

Si comenzamos con el derecho a la herencia, mayoritariamente se puede afirmar que este derecho es consecuencia de la aceptación de la propiedad privada ${ }^{2}$. Sin embargo, aunque el derecho a la herencia se liga ante todo con el derecho a la propiedad, lo cierto es que en aquellos países que establecen asignaciones forzosas (legítimas), la herencia también se vincula necesariamente con la familia y su protección ${ }^{3}$.

En Chile, la Constitución vigente no hace referencia expresa ni a la libertad de testar ni a la sucesión por causa de muerte. Eso sí, el derecho de propiedad es una de las garantías constitucionales esenciales; pero igualmente se establece que "la familia es el núcleo fundamental de la sociedad" y que es deber del Estado "[...] propender al fortalecimiento de ésta" (art. $1^{\circ}$ de la $C P R$ ).

Si partimos desde una perspectiva constitucional, podríamos pensar que establecer limitaciones a la disposición mortis causa de los propios bienes es inconstitucional -debate que se planteó ante el Tribunal Cons-

\footnotetext{
${ }^{2}$ Véase como ejemplo, Elorriaga (2015), pp. 4-8, 19-20 y 101-135.

${ }^{3}$ LePín (2014), pp. 16-19.
} 
titucional alemán y al que haremos referencia- y que, por ello, las asignaciones forzosas serían inconstitucionales.

Por mi parte, concuerdo con la doctrina chilena que defiende que dado que también en la Constitución se afirma que la familia es el pilar fundamental de la sociedad y que el Estado debe protegerla y propender a su fortalecimiento, la existencia de asignaciones forzosas puede considerarse que es una herramienta que el legislador ha decidido emplear para dicha protección y que justifica las limitaciones a la propiedad del causante como medida idónea para lograrla ${ }^{4}$.

Cabe afirmar que el hecho de que constitucionalmente se garanticen tanto el derecho a la propiedad privada como la protección de la familia como institución esencial de la sociedad, determina que en aquellos ordenamientos donde esto sucede, como el chileno, el derecho sucesorio esté llamado a la difícil tarea de conciliar la libertad de disponer con la necesaria protección de la familia. Una de las maneras tradicionales que el legislador emplea para conseguir el citado equilibrio es mediante el establecimiento de asignaciones forzosas a favor de ciertos parientes. Sin embargo, no está de más destacar que el equilibrio entre libertad y protección admite más opciones ${ }^{5}$.

La opción del legislador chileno es que la sucesión sea una institución que, sin dejar de garantizar la libertad de disponer del patrimonio, sirva como medio de protección a la familia, pero ¿̇ue siempre esta la opción del legislador chileno? En sus orígenes, Andrés Bello era partidario de instaurar un sistema de libertad de testar absoluta, pero finalmente la tradición chilena tuvo más peso y el sistema se estructuró sobre la base del sistema castellano de las Partidas, cuyo fundamento era beneficiar a la familia ${ }^{6}$.

Luego, si las asignaciones forzosas se conciben por el legislador como una herramienta idónea para proteger y propender al llamado constitucional del fortalecimiento de la familia como pilar fundamental de la sociedad, resulta oportuno preguntarse a qué familia está llamada a proteger el derecho de sucesiones y qué patrimonio es el que va a tener encomendada dicha función.

\section{1. ¿A qué familia hay que proteger?}

Para contestar de manera correcta a esta pregunta resulta oportuno revisar cuáles son los cambios sociológicos de la familia chilena. Así, podemos

\footnotetext{
${ }^{4}$ Véase mención a dicho debate doctrinal analizado por BARRÍA (2015), pp. 205-206 y ESPADA (2007), pp. 211-230.

${ }^{5}$ Cañizares (2014), pp. 250-255.

${ }^{6}$ Barría (2015), pp. 27-30 y Elorriaga (2019), p. 72.
} 
partir señalando cómo desde un punto de vista sociológico se afirma que en la actualidad la función de la familia es ser una unidad emocional, una red de solidaridad social ${ }^{7}$.

De igual forma, se señala la existencia de numerosos cambios en las estructuras familiares. En primer lugar, en el mundo occidental, se suele destacar que, si bien la familia nuclear perdura, existe una progresiva reducción de su dimensión, que se une a la disminución de la tasa de natalidad y al abandono del medio rural. Además, se afirma el surgimiento de lo que en sociología se denomina "la posnuclearización", es decir, el incremento de los núcleos familiares incompletos por referencia al incremento de las familias monoparentales y a los hogares unipersonales ${ }^{8}$.

En Chile, si acudimos a la segunda entrega de resultados definitivos del censo 2017, elaborada por el INE, podemos constatar que, respecto a los tipos de hogar entre 2002 y 2017 se produjo un aumento de la cantidad de hogares unipersonales, alcanzando el $17,8 \%$ en el último censo y los hogares nucleares biparentales con hijos son el 28,8\%, lo que representa una porción menor respecto del total en comparación con el censo anterior ${ }^{9}$. Del análisis de estos datos se puede concluir que existen varios modelos de organización familiar, pero también una tendencia hacia la reducción de sus integrantes.

Algunos autores, cuando reflexionan sobre esta tendencia, constatan que implica un mayor individualismo en las relaciones familiares con la consiguiente mayor independencia en la toma de decisiones ${ }^{10}$. Existe una pluralidad de tipos familiares que han sido creados al amparo de la autonomía de la voluntad y cuya única posibilidad de funcionamiento es a través de dicha autonomía ${ }^{11}$.

En este sentido, y, si bien resulta bastante controvertida, es relevante traer a colación la definición de familia contemplada en la Ley n. ${ }^{\circ} 21150$ que modifica la Ley n. ${ }^{\circ} 20530$ y que crea el Ministerio de Desarrollo Social y Familia que define:

"Familia: núcleo fundamental de la sociedad, compuesto por personas unidas por vínculos afectivos, de parentesco o de pareja, en que existen relaciones de apoyo mutuo, que generalmente comparten un mismo hogar y tienen lazos de protección, cuidado y sustento" 12 .

${ }^{7}$ FACAL y TORRÉNS (2010), p. 53.

${ }^{8}$ Op. cit., pp. 60-65.

${ }^{9}$ Instituto Nacional de Estadísticas (2017), p. 9.

${ }^{10}$ Rebolledo (2010), p. 28.

${ }^{11}$ Roca (2014), p. 243.

${ }^{12}$ Art. 1.3. a) de la Ley n. ${ }^{\circ} 21150$, de 2019. 
Dicha definición parece acoger la diversidad sociológica de configuración de las familias antes mencionada.

Prosiguiendo con los cambios sociológicos, también se produce lo que algunos autores denominan el "primado conyugal" en sustitución del "primado de los hijos", es decir, el mayor protagonismo o relevancia de la relación conyugal por sobre la filial ${ }^{13}$.

La incorporación de la mujer al trabajo y su aporte de recursos para la familia al igual que el marido, motiva un deseo de disposición conjunta del patrimonio generado en comunidad de vida, tanto en vida como en el momento del fallecimiento con independencia del régimen económico que les rija ${ }^{14}$. Por su parte, el aumento de la esperanza de vida trae consigo la búsqueda de la mayor protección del cónyuge sobreviviente ${ }^{15}$.

Ese aumento de la esperanza de vida también provoca un cambio relevante en la pirámide de población. Así, en Chile, un estudio relativamente reciente publicado por el INE señala que en la pirámide de población en 2050 se proyecta que, en cifras absolutas, el grupo de los mayores de sesenta y cuatro años crecería en más de tres millones de personas con respecto a la situación actual. Además, no solo aumentará la población mayor a sesenta y cuatro años, sino que, también, se modificará la estructura al interior de ese grupo de edad, elevándose el número de personas de ochenta y más $a_{n ̃ o s}{ }^{16}$. Este aumento de la esperanza de vida genera un aumento de los ancianos dependientes, que requieren de cuidados y atención económica y afectiva por parte de hijos o terceras personas. La existencia de estos cuidadores reales demanda ser tenida en cuenta en el ámbito sucesorio ${ }^{17}$.

Otro de los cambios destacables es el aumento de las rupturas matrimoniales, que da lugar a familias monoparentales, pero también reconstituidas, lo que genera nuevos problemas sucesorios a la hora de tener

${ }^{13}$ Rebolledo (2010), pp. 28-29.

${ }^{14}$ Se considera que los problemas relativos a la liquidación del régimen económico matrimonial de sociedad conyugal o de participación en los gananciales, así como de la comunidad de bienes entre convivientes civiles, son cuestiones independientes a los derechos sucesorios atribuidos en la sucesión del causante. Ahora bien, la liquidación de regímenes económico-matrimoniales o convivenciales regulados tiene presente reglas de colaboración entre cónyuges y convivientes. Las reglas sucesorias parten de dicho reparto y ahora, individualmente, tienen presente solo el patrimonio del causante para determinar la sucesión del mismo. Eso sí, en el caso de la atribución preferente de la vivienda familiar según la regla $10^{\circ} \mathrm{del}$ art. 1337 del $C C$ y el momento en el que hacer efectivo dicho derecho, se abre una interesante discusión sobre los bienes que forman parte del patrimonio del difunto. Véase entre otros CAPRILE (1999), pp. 57-58; CorRaL (2005), pp. 91-94 y Elorriaga (1995), pp. 575-577.

${ }^{15}$ Rebolledo (2010), pp. 31-33.

${ }^{16}$ Instituto Nacional de Estadísticas (2018), p. 10.

${ }^{17}$ Rebolledo (2010), p. 29. 
que armonizar la protección entre grupos familiares de origen diverso, a veces, con nueva descendencia en común. Además, no podemos olvidar que la institucionalización de nuevas formas de convivencia (Acuerdos de Unión Civil) o de convivencias de hecho al margen del matrimonio, generan otros modelos familiares que precisan o pueden precisar de una protección en el ámbito sucesorio al ser familias ${ }^{18}$.

A su vez, resulta relevante tener presente la creciente y necesaria preocupación por la protección personal y económica de las personas con capacidades diferentes, estén o no incapacitadas. Los avances médicos determinan la mayor esperanza de vida de dichas personas y, si bien en algunos casos están comenzando a integrarse en el mundo laboral, siguen siendo dependientes de sus progenitores, por lo que estos últimos encuentran ciertas limitaciones para garantizar por vía testamentaria su futuro, una vez que los progenitores fallezcan y su situación de dependencia perdure.

En la encuesta del Segundo Estudio Nacional de la Discapacidad (2015) realizada en Chile se concluye que el 20\% de la población adulta está en situación de discapacidad. De ellos el 8,3\% tiene problemas severos en su desempeño (discapacidad severa) y 11,7 \% están en situación de discapacidad leve a moderada. Además, la situación de discapacidad está estrechamente relacionada con el envejecimiento de las personas y sus ingresos, y afecta en mayor proporción a las mujeres ${ }^{19}$.

En este sentido y desde una perspectiva de género, también es destacable que las labores de cuidado del testador dependiente o discapacitado, a pesar de los cambios sociológicos de las últimas décadas, siguen llevándolas a cabo, en la mayor parte de las ocasiones, las mujeres ${ }^{20}$. Resultaría interesante analizar si en Chile, al igual que ocurre en países como Estados Unidos de América, el testamento se utiliza para premiar al cuidador, o si la última voluntad del causante no tiene relación con una recompensa por dichas labores ${ }^{21}$.

${ }^{18}$ En virtud de un estudio realizado por el Registro Civil, se puede afirmar que desde el año 2012 la progresión de divorcios al año es de una media de cuarenta y seis mil, mientras que la media de matrimonios inscritos durante ese mismo periodo ronda los sesenta y cinco mil anuales. Por su parte los Acuerdos de Unión Civil inscritos desde la entrada en vigor de la ley en 2015 hasta septiembre de 2018 son un total de 21189 . SERviCiO de Registro Civil e Identificación (2017), pp. 9-12.

${ }^{19}$ Respecto a su nivel de ocupación laboral, $42,8 \%$ de las PeSD participan en el mercado laboral y están ocupadas el 51,7\% de las PeSD leve a moderada y el 21,8\% de las PeSD severa. A pesar de dicha ocupación, el 40,4\% de las personas adultas en situación de discapacidad se encuentran en situación de dependencia. Véase SENADIS (2016), p. 12.

${ }^{20}$ En Chile, el 73,9\% de los cuidadores de las personas en situación de discapacidad que cuentan con asistencia personal son mujeres y, en su mayoría, no reciben una remuneración. Véase SENADIS (2016), p. 23.

${ }^{21}$ Torres y García (2014), p. 212. 
Además, prosiguiendo con la perspectiva de género en el derecho de sucesiones, en otros ordenamientos donde este tema se ha estudiado con profundidad se constata que, en general, las mujeres testan más que los hombres, es decir, hacen mayor uso de su autonomía de la voluntad ${ }^{22}$. En Chile también es posible afirmar que existe esa tendencia. Así en 2016, de los 6825 testamentos inscritos en el Registro Nacional de Testamentos en dicho año, 4044 los realizaron mujeres frente a 2781 por hombres ${ }^{23}$.

Luego, es necesario proteger a "una familia" -pilar fundamental de la sociedad-, que ha sufrido importantes cambios en su estructura y en los roles de género que la configuraron inicialmente; cambios que han sido igualmente profundos en lo que se refiere a las relaciones personales y afectivas entre padres e hijos, donde existe una tendencia hacia el individualismo y el distanciamiento físico y afectivo, pero también una mayor preocupación por la protección de las personas dependientes o los descendientes incapacitados. Todos estos cambios de la familia chilena, sin duda deberían de encontrarse presentes en la regulación de los derechos hereditarios, salvo que queramos ser testigos pasivos de la obsolescencia de las instituciones sucesorias.

\section{2. ¿Qué patrimonio se va a destinar a la protección de la familia?}

Señalados los cambios sociológicos, veamos si también existen cambios desde el punto de vista económico, dado que la herencia tiene una dimensión patrimonial evidente.

Cuando hablamos de herencia como instrumento de protección de la familia estamos teniendo en cuenta elementos de política económica y social relevantes; estamos partiendo de nociones como la existencia de un patrimonio familiar y de la contribución a su formación o su procedencia que justifican la transmisibilidad en favor de determinados sujetos y no de otros. Estas afirmaciones hoy son más bien cuestionables.

Sin pretender ser exhaustiva y muy a grandes rasgos, cabe sostener que en un determinado momento histórico y desde un punto de vista económico, en la Europa continental y luego en Latinoamérica, el sistema de legítimas fue la herramienta idónea para asegurar un reparto de la propiedad y lograr con ello aumentar el número de pequeños propietarios y evitar la concentración de la riqueza; pero de igual forma, en las mismas latitudes, la libertad de testar fue el instrumento necesario para garantizar que determinados bienes, esencialmente inmuebles, no perdieran valor

\footnotetext{
${ }^{22}$ Un ejemplo del estudio sobre esta materia en García et al. (2017), pp. 791-807.

${ }^{23}$ Servicio de Registro Civil e Identificación (2017), p. 19.
} 
por su necesaria división y pudieran perdurar en una sola mano al servicio de la familia ${ }^{24}$.

Por otro lado, en esta perspectiva económica, desde la óptica liberal, la autosuficiencia del individuo debía garantizarse por encima de cualquier injerencia o limitación estatal. Así en sus inicios se afirmaba que:

"la prosperidad económica dependía en buena medida de la acumulación de fortunas sobre la base de patrimonios familiares [...] la propiedad privada, la herencia y la libertad de testar como pilares capitales del sistema inglés y, por extensión, norteamericano, frente a la partición hereditaria forzosas de las fortunas de los revolucionarios franceses" ${ }^{25}$.

Encarna Roca también destaca cómo desde el análisis económico del derecho al estudiar la herencia y las relaciones de los hijos con sus padres ancianos advierten la existencia de una especie de pacto intergeneracional donde solo si los padres hicieron grandes inversiones en los hijos, dichos hijos se encargan de su cuidado en la ancianidad ${ }^{26}$. De igual forma, la mayor esperanza de vida, el aumento del periodo de formación profesional, o las dificultades de empleabilidad provocan que la inversión en los hijos se realice hasta edades muy avanzadas, coincidiendo en muchos casos con el periodo de jubilación de los padres que no pueden tener un retorno de dicha inversión. Desde esta perspectiva económica, se afirma que en la actualidad la riqueza de los hijos no se encuentra en la esperanza de una herencia futura, sino en la inversión efectiva que sus progenitores en vida realizaron en su educación ${ }^{27}$.

También se cuestiona el argumento tradicional que contempla la herencia como un patrimonio que se construye sobre la base de los bienes heredados con antelación, configurando una especie de copropiedad intergeneracional que necesariamente debía perdurar en la familia. Hoy la mayor parte del patrimonio que se hereda es resultado del esfuerzo individual, inversiones y emprendimiento personal del causante y no se construye sobre herencias $\operatorname{previas}^{28}$.

${ }^{24}$ Un ejemplo claro es la controversia que en el ordenamiento español tuvo lugar entre la regulación sucesoria que pretendía acabar con los mayorazgos Castellanos y la regulación foral de Navarra y Cataluña, véase CAÑIZARES (2014), pp. 252-256.

${ }^{25}$ Barrio (2011), p. 231.

${ }^{26}$ RocA (2014) destaca los estudios que en el ámbito anglosajón ha realizado Margaret Brinig al respecto. BRINIG (2000), pp. 124-125.

${ }^{27}$ Roca (2014), pp. 215-218 y VAQuer (2007), pp. 10-11.

${ }^{28}$ CÁmara (2011), pp. 285-286 y Walker (2019), pp. 570-571. 
De igual forma se cuestiona la existencia de un patrimonio familiar y la necesidad de su mantenimiento en aquellas regulaciones que tienen por objetivo declarar la interdicción por prodigalidad. En las interdicciones por disipación, al igual que en las asignaciones forzosas, se hace presente la tensión entre la autonomía de la voluntad del titular del patrimonio para disponer de él libremente y la función de protección de la familia que el legislador otorga al patrimonio individual en esos $\operatorname{casos}^{29}$.

Para concluir, desde esta perspectiva económica existe una creciente discusión sobre la sucesión de las pequeñas y medianas empresas. Así, cuando el patrimonio del causante está constituido esencialmente por una empresa o explotación económica, varios autores señalan que los intereses que entran en juego no son solo los de los familiares más próximos, sino un interés social en la conservación de la empresa que justifica que esta no se extinga por la sucesión. En esos casos habrá que precisar en qué medida ese interés social podría prevalecer por sobre los derechos de los legitimarios $^{30}$.

En este ámbito, se ha señalado que para las empresas familiares las asignaciones forzosas se convierten en un gran obstáculo para el desarrollo de la actividad económica y social ${ }^{31} \mathrm{y}$, por ello, recientes reformas legislativas en Europa y Latinoamérica han ido encaminadas a establecer reglas ex122 cepcionales que permiten atribuciones preferenciales de dichas empresas, salvaguardando, eso sí, las asignaciones forzosas, permitiendo efectuar su pago en efectivo y no necesariamente con bienes de la herencia ${ }^{32}$.

Por otro lado, también es relevante hacerse cargo de que la práctica ha desarrollado mecanismos anticipatorios de sucesión (constitución de fundaciones, sociedades de mera tenencia de bienes, entre otras) que permiten el traspaso de activos inter vivos fuera de la normativa sucesoria (y de paso tributaria), lo que desvirtúa la transmisión mortis causa ${ }^{33}$. En este punto y desde una perspectiva de género, hay que tener presente que los estudios empíricos realizados en otros países demuestran que, ante la posibilidad de designar un único sucesor para mantener la empresa familiar indivisa, en la mayoría de los casos la elección es de un varón, lo que supondría un paso atrás en el proceso de participación de las mujeres en la creación, generación y disfrute de la riqueza familiar ${ }^{34}$.

${ }^{29}$ Destaca el análisis que sobre la prodigalidad y su fundamento realiza BARRIO (2012), pp. 297-440.

${ }^{30}$ Barría (2018), pp. 61-108; PARRA (2009), pp. 497, 505-507 y NAVAS (2011), pp. 112-125.

${ }^{31}$ Magariños (2005), pp. 21-22.

${ }^{32}$ Podemos poner como ejemplos en este sentido el artículo 831 del Code francés, el art. 1406, inc. $2^{\circ}$ del Código Civil español o el art. 2380 del Código Civil argentino.

${ }^{33}$ Parra (2009), pp. 471-474 y Elorriaga (2019), p. 94.

${ }^{34}$ Torres y García (2014), pp. 212-213. 
En virtud de todo lo señalado, podemos afirmar que los cambios desde el punto de vista de las relaciones familiares no son solo sociológicos, sino que como hemos podido apreciar en este apartado, también lo son de carácter económico. En la actualidad la configuración del patrimonio sucesorio y el fundamento de su transmisibilidad a determinados familiares también pueden ser objeto de cuestionamiento, si tenemos presente la lógica económica y patrimonial de nuestros días.

\section{OPCIONES LEGISLATIVAS Y DOCTRINALES}

\section{Algunas respuestas legislativas}

Tal y como se indicó al inicio del presente artículo, hay que reiterar que la decisión sobre el equilibrio o preeminencia de la autonomía de la voluntad o la imposición de asignaciones para proteger a la familia es una decisión exclusiva de política legislativa.

$\mathrm{Si}$ analizamos, grosso modo, los sistemas de derecho sucesorio desde el punto de vista del derecho comparado, es sabido que la distinción elemental es entre los sistemas angloamericanos del common law en los que rige la libertad de testar y los sistemas legitimarios clásicos en los que determinados familiares tienen derecho a recibir necesariamente una parte de los bienes de la herencia.

Sin embargo, estudios recientes ponen en evidencia que en los sistemas donde había libertad de testar absoluta, dicha libertad está siendo cuestionada y sufriendo ciertas limitaciones. Así, autoras como M. Ángeles Parra ponen el ejemplo de Estados Unidos de América, donde en aquellos Estados donde hay libertad de testar absoluta, los padres por lo general hacen disposiciones en favor de sus hijos. Por otro lado, solo un 1\% de los testamentos es impugnado y la motivación de dicha impugnación sucede casi exclusivamente cuando la disposición se realiza en favor de terceros existiendo descendencia o familiares cercanos. En esos casos, los jueces suelen fallar en contra de la disposición del testador, puesto que de forma mayoritaria consideran que la voluntad de dicho testador está viciada o cooptada, dando lugar a lo que la doctrina estadounidense ha denominado "el control moral de los jueces", pues todo aquello que no responda a la hipotética voluntad típica de un causante medio (órdenes de sucesión intestada) quedará bajo sospecha $^{35}$.

${ }^{35}$ PARRa (2009), p. 487. Esta autora pone como ejemplo de dicho control moral sentencias donde los jueces afirmaban que el testador actuaba contra "lo que es natural" o 
Por otro lado, en Europa, tal y como señala Aurelio Barrio, en la actualidad ya no existe, en estricto rigor, un sistema que admita la libertad de testar sin limitaciones, puesto que en Inglaterra y Gales dicha autonomía de la voluntad fue restringida con la Inheritance Act de las llamadas family provisions, donde, si bien no hay clases concretas de parientes con derecho a recibir bienes hereditarios, existe un control judicial donde el juez de modo discrecional puede disponer en favor de sujetos dependientes del fallecido la provisión de bienes necesarios para sobrevivir o llevar un nivel de vida semejante al que se llevaba antes del fallecimiento del causante. Es más bien un crédito alimenticio que grava la herencia del causante, asegurando que las necesidades básicas de la familia queden cubiertas tras el fallecimiento ${ }^{36}$. También, desde la práctica testamentaria anglosajona han constatado que el envejecimiento progresivo de la población ha traído consigo el aumento de disposiciones en favor de los hijos - por lo general hijas- que les cuidan y atienden en la vejez ${ }^{37}$.

Respecto de los países que cuentan con asignaciones forzosas (legítimas), las últimas tendencias han procedido a su reducción, pero de forma bastante mitigada. Así en Alemania en 2010 y tras la sentencia del Tribunal Constitucional alemán, que en 2005 declaró constitucionalmente protegida la legítima de los hijos en virtud del principio de solidaridad 124 intergeneracional familiar ${ }^{38}$, se mantiene la legítima y sus cuotas, pero se producen reformas en materia de causales de desheredación, computación de donaciones y formas de pago $^{39}$. En el derecho belga se mejora la situación del cónyuge y los ascendientes pierden la condición de legitimarios si concurren con el cónyuge ${ }^{40}$. Por su parte, en el derecho francés en 2006 se suprimió la legítima de los ascendientes, se modificó la naturaleza de la acción de reducción de donaciones que de real pasa a crediticia y se admitieron los pactos sucesorios, eso sí manteniendo la inexistencia de causales de desheredación, pues no se puede privar a los legitimarios de su porción ${ }^{41}$.

De igual forma, en otros países, se han llevado a cabo reformas que flexibilizan la regulación de las asignaciones forzosas, introduciendo me-

que "no actúa como un padre juicioso", por establecer disposiciones en favor de la enfermera que lo cuidó, o del amante -sobre todo en relaciones homosexuales- o de ciertas organizaciones religiosas en lugar de a favor de los hijos.

${ }^{36}$ Para un estudio histórico profundo sobre esta materia y en este sentido véase BARRIO (2011), pp. 269-300.

${ }^{37}$ BARRIo (2011), p. 274, nota 1104 y PARRA (2009), pp. 487-488.

${ }^{38}$ Tribunal Constitucional Federal alemán, sentencia de 19 de abril de 2005.

${ }^{39}$ Röthel (2008), pp. 14-15, 52-73.

${ }^{40}$ Parra (2009), pp. 490-492.

${ }^{41}$ Malaurie y Brenner (2018), pp. 401-416 y 491-649. 
didas destinadas a proteger a aquellos parientes en especial vulnerables y dependientes en atención a su situación de discapacidad ${ }^{42}$.

Por su parte, dentro de nuestros países vecinos, hay que destacar dos recientes reformas en esta materia que parecen hacerse cargo de los cambios socioeconómicos analizados. Por un lado, en Argentina, en su nuevo Código Civil y Comercial de la Nación, se mantuvo el sistema romano de sucesión universal y personal, pero se disminuyó la porción destinada a asignaciones forzosas y actualmente el testador puede disponer de forma libre de un tercio de sus bienes, se facilitaron los medios de pago de la legítima y se introdujeron medidas de protección de la empresa familiar ${ }^{43}$. Y, por su parte, en Colombia, entró en vigor en enero de 2019 la reforma al Código Civil destinada a aumentar la libertad testamentaria y que, entre otras reformas, prevé la eliminación de la cuarta de mejora, siendo de libre disposición la mitad del patrimonio del causante ${ }^{44}$. En Chile, se presentó el 11 de diciembre de 2018 un proyecto de ley para fortalecer la libertad de testar eliminando la cuarta de mejoras (Boletín n. $\left.{ }^{\circ} 12301-07\right)$, lo que ha sido valorado como una reforma oportuna por parte de la doctrina ${ }^{45}$.

\section{Las principales respuestas doctrinales}

Si nos centramos en la doctrina, existen argumentos a favor y en contra de las asignaciones forzosas de ciertos familiares que son reiterados y semejantes en muchos autores y latitudes.

Intentando hacer una síntesis de los argumentos más tradicionales a favor de la libertad de testar, se afirma que en la actualidad y desde un punto de vista sociológico, dada la evolución que ha experimentado la familia desde la época de la Codificación, la concepción de la legítima como una expresión de solidaridad intergeneracional ha quedado obsoleta. Se parte de que la libertad de testar es un presupuesto del derecho de propiedad y que su garantía debe ser primordial, superando consideraciones familiares. Se afirma que carece de fundamento entender que hay una copropiedad familiar, ya que hoy la mayoría de los bienes que se heredan no provienen de un patrimonio familiar previo, sino que son

${ }^{42}$ Por ejemplo, en España la Ley 41/2003, de 2003, modificó la regla de intangibilidad de la legítima en favor del establecimiento de gravámenes destinados a proteger a los descendientes discapacitados (art. $808 \mathrm{del}$ CC) y en el mismo sentido el art. 2448 del Código Civil argentino vigente.

${ }^{43}$ Véase en este sentido, la nueva redacción de los arts. 499, 527, 1010, inc. $2^{\circ}, 2380$ y 2381 del Código Civil y Comercial de la Nación.

${ }^{44}$ Ley n. ${ }^{\circ} 1934$, de 2018 por medio de la cual se reforma y adiciona el Código Civil.

${ }^{45}$ Rodríguez (2019). 
el resultado directo del trabajo e inversiones del fallecido ${ }^{46}$. Además, se considera que el uso de la libertad de testar permitiría hacer una auténtica justicia entre los familiares que dependen del testador, porque al no tener todos los mismos méritos, ni aptitudes, el causante podría distribuir los bienes conforme a dichos criterios, reforzando su autoridad. Según estos autores, desde un punto de vista económico, reforzar la libertad del testador permitiría mantener el patrimonio familiar uniforme y que el causante eligiera al mejor sucesor, sin necesidad de divisiones ineficientes ${ }^{47}$.

Por su parte, los defensores de las legítimas han apoyado su mantenimiento basándose en argumentos de ética familiar, que se enlazan con ideas de copropiedad de un patrimonio familiar intergeneracional y con la obligación de mantener y garantizar la subsistencia de los parientes más próximos. Los partidarios de dichos argumentos sostienen que no es justo un sistema que permita enriquecerse a extraños a expensas de la familia, sobre todo en aquellos casos en los que existen sujetos dependientes o incapaces ${ }^{48}$.

También es posible identificar argumentos más recientes como la defensa de la legítima como una convicción de que el Estado debe tutelar a determinados parientes otorgándole el derecho a ciertos bienes y protegerlos de quien, teniendo dichos bienes y parientes, dispone de ellos en favor de terceros, más allá de un mero reproche moral o social. Se entiende que las asignaciones forzosas son una forma de proteger y dar consistencia a la familia cuya protección suele estar garantizada constitucionalmente en la mayoría de los sistemas, por lo que, si bien es posible su flexibilización, no se aboga por su supresión ${ }^{49}$. De esa forma, la existencia de las asignaciones forzosas se convierte en una protección del testador frente a la manipulación por terceros o, incluso, por familiares cercanos en los momentos de mayor vulnerabilidad, que suelen ser los próximos al otorgamiento del testamento.

De igual forma se defiende la existencia de la legítima como una forma de protección de todos los hijos en las familias reconstituidas o sucesivas donde puede que el contacto con los progenitores se vaya debilitando,

${ }^{46}$ M. Ángeles Parra destaca: “[...] no existe tal patrimonio familiar en el sentido de que su origen se conecta a la existencia de una familia, no ha sido recibido de los ascendientes para ser transmitido a los descendientes; ha sido obtenido con el propio trabajo personal y destinado de manera preferente al sostenimiento de la familia y a sus necesidades de alimento y educación, sin que los descendientes que se habrán labrado su propio destino vital y profesional dependan de su adquisición para su subsistencia”. PARRA (2009), p. 504.

${ }^{47}$ Entre los autores nacionales que son favorables a una mayor libertad de testar por los motivos señalados podemos destacar a Claro (2015), p. 247; Domínguez y Domínguez (2011), pp. 962-963; RodríGuez (2002), p. 307 y Rodríguez (2019).

${ }^{48}$ Véase la recopilación de los argumentos esgrimidos en este sentido realizada por LACruz (2004), p. 318 y ss.; LóPez (1994), pp. 51-53 y TORRES (2006), p. 220.

${ }^{49}$ Delgado (2006), p. 128 y ss.; Parra (2009), p. 498 y Torres (2006), p. 227. 
pero de igual forma se defiende la autonomía para realizar repartos no necesariamente igualitarios entre ellos ${ }^{50}$.

En las recientes reformas legislativas mencionadas, también se ha acogido una demanda doctrinal clásica que solicitaba la supresión de la legítima de los ascendientes teniendo en cuenta datos socioeconómicos y la esperanza de vida ${ }^{51}$. Si bien es cierto que los datos pueden reforzar dicha petición, algunos autores critican dicha pérdida de derechos legitimarios de los ascendientes, porque consideran que, en una sociedad envejecida con un decreciente nivel de vida relativo, es contrario a la justicia suprimir la legítima de los ascendientes, pues dicha legítima sería la plasmación jurídica de la deuda moral contraída por los descendientes por su cuidado y educación ${ }^{52}$. Por su parte, otros autores entienden que estos argumentos, si bien pueden ser válidos para una sucesión intestada, no parecen tan oportunos cuando de lo que se trata es de imponer límites a la libertad de testar ${ }^{53}$.

No obstante, estoy de acuerdo con Encarna Roca, que matiza estas opiniones, señalando que, si bien parece oportuna la citada supresión de la legítima de los ascendientes,

"[...] nada impediría que un sistema de retornos sucesorios permitiera a aquellos progenitores que dependen económicamente de un hijo fallecido sin descendencia, obtener una participación en la herencia de su hijo en esas circunstancias, en una solución parecida a la establecida en la inglesa Inheritance (Provision for Family and Dependents) Act 1975 o bien cuando en este mismo caso, ha efectuado fuertes inversiones en la educación de este hijo" ${ }^{54}$.

Al final se destaca por la doctrina la tendencia existente en las relaciones familiares actuales que lleva a que los testadores deseen fortalecer la posición del viudo o de la pareja institucionalizada en detrimento de otros familiares, generalmente de los hijos; tendencia que varias reformas legislativas europeas han tenido en cuenta ${ }^{55}$.

Por todo lo señalado, en la actualidad algunos autores consideran que todos los anteriores cambios deberían reflejarse en una reforma legislativa

${ }^{50}$ SERnA (2010), pp. 260-261.

${ }^{51}$ Como ejemplo en el ordenamiento español véanse las referencias estadísticas y socioeconómica de VAQUer (2007), p. 9 y, recientemente en Chile, WALKer (2019), pp. 572-574.

${ }^{52}$ Moreu (1997), p. 99.

${ }^{53}$ PARra (2009), p. 502.

${ }^{54}$ Roca (2014), pp. 216-217.

${ }^{55}$ Véase el análisis de la regulación europea comparada sobre esta materia y las posibilidades de unificación en Pintens (2011), pp. 8-23. 
que implicase una reducción cuantitativa de los derechos de los descendientes; la eliminación de la cuarta de mejora ${ }^{56}$, o su conversión en una legítima de alimentos ${ }^{57}$; e igualmente se plantean medidas que favorezcan la continuidad del patrimonio familiar empresarial ${ }^{58}$ o que vayan destinadas a proteger el patrimonio de personas dependientes o discapacitadas.

\section{LA SOLIDARIDAD FAMILIAR COMO FUNDAMENTO DE LA ASIGNACIÓN FORZOSA}

De todo lo anterior puede concluirse que el establecimiento de un equilibrio entre los intereses de proteger la familia y asegurar la autonomía de la voluntad del causante al momento de hacer testamento es una ardua tarea de no fácil consecución, sobre todo porque implica una reflexión de los motivos legislativos que justifican la atribución de derechos legitimarios en los distintos ordenamientos. El fundamento de la asignación forzosa tiene un importante peso ideológico y cultural ${ }^{59}$.

Si nos vamos a los extremos de la balanza, una autonomía de la voluntad absoluta en el ámbito sucesorio puede llevarnos a desproteger a sujetos dependientes y desvirtuar una de las funciones tradicionales de protección de la familia a través de la solidaridad intergeneracional entre sus integrantes.

Sin embargo, en el otro extremo, una limitación excesiva de dicha autonomía también puede impedir una mayor protección de los parientes realmente dependientes o destruir el desarrollo económico al que destinó su esfuerzo personal el causante cercenando la libre disposición de sus bienes, etcétera.

Luego, en los países que establecen un deber del Estado de proteger a la familia, ¿cómo debe entenderse la función de las asignaciones forzosas?, ¿tiene que configurarse como un mecanismo imprescindible para la protección de la familia o como una garantía exigible solo por ciertos familiares en casos de necesidad?, ¿ en realidad se trata de un límite anacrónico e injustificado a la autonomía de la voluntad que debe suprimirse y proteger a la familia por otras vías?

${ }^{56}$ Corral (2008), p. 10; Rodríguez (2010), pp. 664-665; Rodríguez (2019) y Walker (2019), pp. 574-576.

${ }^{57}$ Entre otros, Barrio (2012), pp. 483-579; PANTAleón (2003), p. 13 y Rodríguez (2010), p. 667.

${ }^{58}$ BARRía (2018), pp. 83-100.

${ }^{59}$ En este sentido son famosas las palabras del barón de Montesquieu cuando afirma: "alimentar a los hijos es una obligación de derecho natural; darles la sucesión es una obligación de derecho civil o político", referenciado entre otros por BARRIO (2012), p. 503. 
Autoras como M. Ángeles Parra señalan:

"[...] los argumentos sociológicos en apoyo del reconocimiento de una mayor flexibilización de las legítimas y su sustitución, en su caso, por un derecho de alimentos en favor de los descendientes que se encuentren en situación de pedirlos, encuentran una mayor justificación en clases medias, trabajadoras por cuenta ajena, empleados y pequeños profesionales, en las que el patrimonio personal procede del propio trabajo y que, además, han proporcionado a sus hijos una educación” ${ }^{60}$.

Esta conclusión serviría para determinar que la legítima tiene como función favorecer la subsistencia en exclusiva de los legitimarios en estado de necesidad o dependencia. Así, precisamente teniendo presente como fundamento la posible situación de necesidad, la reforma operada en Luisiana en 1996 la limitó en favor de los descendientes solo a los hijos menores de veinticuatro años, a los discapacitados de forma permanente y a los que tal vez estarían discapacitados en un futuro debido a una enfermedad hereditaria incurable ${ }^{61}$. En este caso, su fundamento es asistencial para aquellos familiares que se encuentren en situación de necesidad al momento del fallecimiento del causante.

Sin embargo, los detractores de los límites a la libertad de testar ponen en evidencia que, teniendo en cuenta estadísticas sobre la mayor esperanza de vida, hoy, los legitimarios ya han alcanzado la estabilidad económica y profesional cuando heredan, por lo que difícilmente se van a encontrar en situación de necesidad. Sería una regla que se aplicaría de forma marginal, por lo que en ese caso sería preferible que el testador pueda disponer siempre de sus bienes de manera libre.

Llegados a este punto en la argumentación, sería preciso retomar la pregunta de Encarna Roca, sobre si partiendo de la realidad sociológica y económica actual lo que procede es considerar que la legítima es exclusivamente un derecho moral. La citada autora lo niega de modo rotundo, siguiendo a John Eekelaar y Ronald Dworkin, pues afirma que la herencia en sí misma considerada no deriva de un derecho moral previo, dado que existen varias formas de organizar los efectos del fallecimiento; la legítima es un derecho legal, pero no moral, ya que nadie está legitimado para reclamar la titularidad sobre unos bienes en cuya adquisición no ha participado. Eso sí, concluye que afirmar que no sea un derecho moral,

${ }^{60}$ PARra (2009), p. 539.

${ }^{61}$ Art. 1493 del Código Civil de Luisiana. Disponible en https://lcco.law.lsu.edu/?uid= $53 \& v e r=$ en\#53 [fecha de consulta: 24 de agosto de 2020]. 
tampoco significa que la ley no pueda crear un derecho a participar por vía sucesoria de la riqueza creada por el causante ${ }^{62}$.

Si entendemos que es un derecho legal que no debe suprimirse, esto no obsta a que se modifiquen sus reglas de atribución. En este sentido, muchas de las reformas legislativas han flexibilizado su regulación mediante, por ejemplo, la ampliación de las causas de desheredación, dando paso a cláusulas abiertas o más amplias como la desheredación por falta de trato familiar. Estas reformas, si bien dan más margen a la autonomía de la voluntad del testador, no dejan claro el fundamento de por qué ciertos parientes deben verse favorecidos con una asignación. Autoras como Esther Arroyo y Esther Farnós han puesto de manifiesto que este tipo de modificaciones, a la hora de aplicarse, conducen a dejar al arbitrio de los tribunales la elección entre el testador abandonado o mal tratado por sus parientes y los legitimarios que entienden que son desheredados de forma injusta. Ante esta disyuntiva no es claro a quién van a preferir los jueces. Como señalan estas autoras, mientras no se precise cuál es el fundamento del legislador al garantizar las asignaciones forzosas, reformas de este tipo solo incrementan la litigiosidad, la inseguridad jurídica y no se traducen necesariamente en resultados más equitativos entre libertad y protección de la familia ${ }^{63}$.

130 Por otro lado, si retomamos la inquietud relativa a que el patrimonio del causante esté constituido esencialmente por una empresa o explotación económica, como ya mencionamos, los intereses que entran en juego no son solo los de los familiares más próximos, sino un interés social en la conservación de la empresa y que esta no se extinga por la sucesión ${ }^{64}$. Luego, en estos casos, además de la autonomía de la voluntad y de la solidaridad intergeneracional, habrá que precisar en qué medida el mantenimiento del interés social de la empresa o explotación económica podría prevalecer sobre los derechos de los legitimarios.

En esta materia, concuerdo con M. Ángeles Parra, que solo se podrá garantizar esta libertad de testar a la hora de atribuir la empresa familiar, si se regulan cautelas como la carga del beneficiario de continuar con la explotación familiar, la prohibición de venderla o, incluso, la imposición al causante de la necesidad de escoger cuál es el sucesor más idóneo para continuar con dicha empresa, ya que de lo que se trata es de proteger la empresa familiar no de proteger los intereses empresariales por sobre los intereses familiares de forma general ${ }^{65}$.

${ }^{62}$ Roca (2014), pp. 231-233 y referencia de esta autora al texto de EEKELAAR (1993), p. 60 y ss.

${ }^{63}$ Arroyo y Farnós (2015), p. 23.

${ }^{64}$ Parra (2009), pp. 539-540.

${ }^{65}$ Op. cit., p. 541. 
Llegado a este punto de la argumentación, consideramos al igual que Antonio Vaquer, que lo esencial es precisar en primer lugar si nos encontramos dentro de los países que consideran la regulación de la legítima como una forma de protección de la familia que debe ser garantizada. Si estamos dentro de estos países, que como se argumentó, es el caso de Chile, la siguiente pregunta esencial es cuál es el fundamento de la concreta asignación forzosa en favor de ciertos familiares.

$\mathrm{Al}$ igual que el mencionado autor, entendiendo que respecto del fundamento solo tenemos dos posibilidades:

i) la asignación forzosa es efectivamente un derecho legal de determinados parientes o

ii) se trata de una manifestación del principio de solidaridad familiar ${ }^{66}$. Si lo consideramos un derecho del asignatario forzoso, es un deber unilateral del causante respetarlo. Sin embargo, si consideramos que es una manifestación del principio de solidaridad familiar, cabe entender que la reciprocidad va implícita en el término y, por ello, el causante podría tener un margen legítimo para acumular, reducir o negar una atribución. La autonomía de la voluntad del testador tendría un margen más amplio que le permitiría actuar conforme a su realidad familiar concreta y no hipotética o presunta ${ }^{67}$.

Por lo tanto, en Chile, a pesar de los cambios sociológicos evidenciados respecto de los modelos familiares y del mayor protagonismo de la autonomía de la voluntad presente en varias reformas legislativas, el legislador sucesorio chileno entre libertad de testar y asignaciones forzosas, sigue concibiendo el mantenimiento de las asignaciones forzosas como un mecanismo idóneo de protección de la familia, que como pilar fundamental de la sociedad debe ser fortalecido teniendo mayor peso en la balanza que la libertad de testar del causante ${ }^{68}$.

${ }^{66}$ VAQUer (2017), p. 2.

${ }^{67}$ En este sentido y como ejemplo de reforma legislativa con un criterio de solidaridad familiar, Antonio Vaquer menciona la última reforma del derecho austriaco cuyo $\$ 770.5$ del $A B G B$ considera causa de desheredación el incumplimiento grave de deberes familiares, lo que se complementa con el $\$ 776 \operatorname{del} A B G B$ que faculta al causante a reducir a la mitad la cuota del legitimario que no haya mantenido con el causante una relación como es la usual entre parientes o no la haya mantenido por un largo periodo de tiempo, siempre que el causante no haya promovido o dado motivos, sin razón que lo ampare, a dicha ausencia de relación. VAQUER (2017), p. 15.

${ }^{68}$ Recientemente autoras como M. Agnes Salah han destacado que también la concepción de la igualdad en el ámbito del derecho sucesorio debe ser resaltada. Así, concuerdo con la autora cuando señala: "La ley y la dogmática tienen el desafío de incorporar criterios más sofisticados de igualdad en el ámbito sucesorio. Con ello, se puede alcanzar una igualdad ya no matemática, porcentual o numérica, sino que una igualdad que tome en consideración la situación y dignidad de las personas”, SALAH (2019), p. 558. 
Y sobre la posibilidad de flexibilizar la regulación de las asignaciones forzosas, de nuevo, el legislador chileno y gran parte de la doctrina nacional interpretan la norma vigente como el derecho del legitimario por sobre criterios de solidaridad familiar, donde la autonomía del testador podría tener algo más de protagonismo. En este sentido, sirva como ejemplo que respecto de las causales de desheredación se afirma que las causas por las que se puede desheredar a un legitimario son solo las enumeradas en el art. 1208 del Código Civil, con independencia de que el comportamiento que pudiera llevar a cabo el legitimario respecto del causante pueda llegar a considerarse más grave que los contemplados en el precepto ${ }^{69}$. Para la mayoría de la doctrina chilena se debería respetar el derecho a suceder al causante, aunque, por ejemplo, el legitimario llevara más de veinte años sin relacionarse con el causante ${ }^{70}$.

Estoy de acuerdo con que las asignaciones forzosas no sean suprimidas, pero considero que su regulación debe ser más flexible teniendo en cuenta su fundamento de atribución. En mi opinión, lo esencial es plantear un nuevo enfoque respecto del fundamento de las asignaciones forzosas. Es evidente que la libertad de testar absoluta tiene riesgos manifiestos para ordenamientos donde la protección de la familia es un pilar esencial del ordenamiento. Si la familia se protege por su arraigo social, cultural y constitucional, otorgarle protección a través de las asignaciones forzosas tendrá más sentido que privilegiar criterios individualistas o meritocráticos en función de los intereses del causante titular del patrimonio.

$\mathrm{Si}$ aceptamos esta función protectora de la familia de la asignación forzosa, esto no significa que en aquellos ordenamientos donde se opte

${ }^{69}$ Elorriaga (2015), p. 547.

${ }^{70} \mathrm{Si}$ bien en algunos casos se centra la discusión en la duración de la relación, considero que la cuestión de fondo es el fundamento de la asignación forzosa. Lo esencial es cuestionarse si en el matrimonio está justificado que se atribuyan asignaciones forzosas por el hecho de tener vigente el vínculo matrimonial, aunque no exista una comunidad de vida efectiva, como es el caso de los separados de hecho. O si en el caso de los convivientes civiles, por el hecho de registrar una convivencia civil se tienen que reconocer derechos legitimarios con independencia de que en la realidad exista o no una convivencia real entre los firmantes del Acuerdo de Unión Civil. Y, finalmente, si en los casos de parejas de hecho, existiendo una convivencia efectiva donde quede acreditada la ayuda mutua y la comunidad de vida, por el hecho de no existir formalización se debe negar el reconocimiento de asignaciones sucesorias forzosas. $\mathrm{Si}$, como se plantea en el siguiente artículo, la ratio legis de la asignación forzosa es la solidaridad familiar y no un derecho adquirido, constatada en los hechos dicha solidaridad, exista o no una formalización, habría que reconocer la asignación sucesoria. Si en todas las situaciones anteriores se acredita la existencia de solidaridad familiar, en mi opinión, el principio de igualdad no debería verse sacrificado con el único fin de alcanzar una mayor seguridad jurídica (vínculo o inscripción), cuando de lo que se trata es de garantizar la protección constitucional de la familia a través de la atribución de asignaciones forzosas. 
por tal protección familiar a través del reconocimiento de asignaciones forzosas, solo pueda garantizarse esta protección mediante el estableciendo derechos a cuotas o elevadas porciones del patrimonio del fallecido.

De igual forma, limitar el fundamento de la atribución sucesoria en favor de ciertos familiares solo a estados de necesidad supone transformar la asignación sucesoria en una especie de derecho de alimentos. Esta forma de entender la institución de la legítima implica que se considera que no es una herramienta para garantizar y proteger a la familia como red de solidaridad o unidad emocional en sentido amplio, sino que es un derecho individual excepcional para casos donde sea necesario garantizar la satisfacción de las necesidades básicas de ciertos familiares para su subsistencia, lo que también es matizable. En mi opinión, la situación de necesidad no creo que deba ser la condición para el otorgamiento de asignaciones sucesorias, sino que lo esencial es la constatación de una solidaridad familiar efectiva que justifique garantizar la atribución de una asignación tras el fallecimiento, pero que igualmente legitime su pérdida en los casos en los que dicha solidaridad no sea real.

Llegados a este punto, resulta necesario precisar qué es lo que entendemos por solidaridad. En este sentido no asemejamos solidaridad con equidad o distribución igualitaria, ya que, como demuestran recientes estudios, no hay una evidencia empírica de que el reparto igualitario de la sucesión de un determinado porcentaje de ella produzca un efecto real de redistribución de la riqueza entre los asignatarios forzosos ${ }^{71}$. Luego, más que hablar de una solidaridad familiar redistributiva, entiendo que lo relevante es la solidaridad dentro y en la familia. Esto significa que el ordenamiento garantiza la asignación forzosa exclusivamente a aquellas personas merecedoras de ella, que, de forma real y no presunta, hayan prestado ayuda al causante, generado una comunidad de vida y afectos con él que, por regla general, habrá sido prolongada en el tiempo o se hayan prestado asistencia en situaciones de necesidad o discapacidad. Se les garantiza la asignación forzosa, porque su comportamiento en vida es reflejo de la solidaridad familiar que constitucionalmente se pretende proteger o garantizar como pilar fundamental de la sociedad a través de dicha asignación ${ }^{72}$.

De no existir ese trato familiar solidario, o encontrándonos directamente ante situaciones de abandono o falta grave del cumplimiento de deberes familiares, sería legítimo privar a dichos familiares de la asignación forzosa, dado que no se trata de derechos adquiridos, sino de atribuciones legales basadas en la constatación de la solidaridad familiar que justifica

${ }^{71}$ Referencia de VAQUer (2017), p. 16, nota 59, a un reciente estudio sueco en sobre esta materia.

${ }^{72}$ Op. cit., pp. $20-21$. 
su atribución y protección. Esto implicaría, por ejemplo, flexibilizar la interpretación de las causales de desheredación por incumplimiento de dicha solidaridad familiar, entendida como fundamento de la asignación forzosa y del deber de cuidado y respeto entre familiares. En virtud de todo lo argumentado, considero que la solidaridad familiar sería el peso necesario para equilibrar los platos que tensan la balanza sucesoria entre la libertad de testar absoluta y el derecho legitimario adquirido.

\section{Conclusión}

Para concluir se puede afirmar que, si bien la sociedad actual considera modelos familiares que no se tuvieron presentes al momento de la Codificación, se sigue manteniendo el mismo esquema sucesorio para protegerlos, quedando desfasado de los modernos planteamientos sociales.

Factores sociológicos como las mayores inversiones en los hijos (educación) y su prolongación en situación de dependencia (desempleo juvenil, aumento de la edad de formación), la prolongación de la esperanza de vida o, factores económicos como que el capital ya no está basado en la propiedad de bienes materiales, sino en la capacidad para obtener ingresos,

134 hacen tambalear el fundamento y justificación de las normas sucesorias tradicionales. Si a todo lo anterior unimos que los grandes patrimonios se refugian en sistemas alejados del derecho sucesorio (sociedades, fundaciones...), nos queda un derecho de sucesiones obsoleto que es necesario revisar profundamente. Es necesario buscar aquellos criterios que sean más idóneos para proteger a la familia actual y sus nuevas necesidades, eso sí, sin sacrificar la libertad de testar del causante.

Como hemos podido señalar, la vida es mucho más rica en acontecimientos que la imaginación del legislador en previsiones, pero desde la doctrina estamos llamados a detectar y proponer soluciones a los conflictos sociales que tengan lugar en el marco constitucional. Considero que en el tema del fundamento de las asignaciones forzosas esto puede conseguirse poniendo como ratio legis de la asignación forzosa la solidaridad familiar por sobre una concepción de derecho adquirido garantizado. Por lo tanto, si existen familiares que actuaron de forma solidaria con el causante en vida es legítimo que se les garantice una asignación. Dicha asignación forzosa se convierte en una forma de protección a las relaciones familiares cuyo fortalecimiento se pretende garantizar constitucionalmente, esto es, aquellas basadas en la solidaridad y ayuda mutua y que configuran el pilar fundamental de la sociedad, por encima del individualismo. Sin embargo, si dichas personas incumplieron sus deberes familiares para con el causante, este tendrá libertad para no realizarles ninguna asignación, 
ya que su atribución carecería de fundamento, pues esta se justifica por la solidaridad y no por un derecho adquirido garantizado que depende solo de la constatación formal de la existencia de un vínculo o un registro.

Si la asignación forzosa no se concibe como un derecho garantizado, sino como una manifestación del principio de solidaridad familiar, se justifica su atribución en la reciprocidad que va implícita en el término. Precisamente la concurrencia de la solidaridad familiar es lo que permite al causante acumular, reducir su cuota o negar una asignación forzosa (desheredación). La autonomía de la voluntad del testador tendría un margen más amplio que le permitiría actuar conforme a su realidad familiar concreta. La solidaridad familiar implica que lo que se garantiza a los herederos forzosos no es una igualdad en un sentido matemático o porcentual por el hecho de tener vínculos familiares, sino un reparto no necesariamente uniforme basado en la realidad familiar concreta que permite incentivar aquellas relaciones familiares cuyo fortalecimiento se pretende garantizar de manera sucesoria.

\section{Bibliografía CITADA}

ARROYO, Esther y Esther FARNós (2015). "Entre el testador abandonado y el legitimario desheredado. ¿A quién prefieren los tribunales". Indret, n. ${ }^{\circ}$ 2. Barcelona.

BARRÍA, Manuel (2015). Asignaciones forzosas y libertad de testar. Santiago: Editorial Thomson Reuters.

BARRÍA, Manuel (2018). "La empresa familiar o explotación agropecuaria: mecanismos que permitan su continuidad a la muerte de su titular a la luz del Derecho sucesorio chileno". Revista Chilena de Derecho Privado, n. ${ }^{\circ} 31$. Santiago.

BARrio, Aurelio (2011). La evolución de la libertad de testar en el "Common Law" inglés. Navarra: Editorial Thomson Reuters.

BARrio, Aurelio (2012). El largo camino hacia la libertad de testar. De la legítima al derecho sucesorio de alimentos. Madrid: Editorial Dykinson.

BRInig, Margaret (2000). From Contract to Covenant. Below the Law and Economics of the Family. London: Harvard University Press.

CÁmARA, Sergio (2011). "Freedom of testation, legal heritance rights and public order under Spanish Law”, in Esther ARroYo \& Miriam ANDERSON (eds.). The Law of Succession: Testamentary Freedom. European perspectives. Groningen: Europa Law Plublishing.

Cañizares, Ana (2014). "Legítimas y libertad de testar", en Andrés Domínguez y María Paz García (dirs.). Estudios de derecho de sucesiones. Madrid: Editorial La Ley Wolters Kluwer.

CAprile, Bruno (1999). "El Derecho de adjudicación preferente: Comentario al artículo 1337 n $^{\circ} 10$ del Código Civil”. Revista de Derecho, n. ${ }^{\circ}$, vol. viI. Concepción. 
Claro, Luis (2015). Explicaciones de derecho civil chileno y comparado. Santiago: Editorial Jurídica de Chile, vol. VII.

Corral, Hernán (2005). La vivienda familiar en la sucesión del cónyuge. Santiago: Editorial Jurídica de Chile.

Corral, Hernán (2008). "Por la democratización del testamento". El Mercurio, Santiago, 27 de septiembre de 2008.

Delgado, Jesús (2006). "Una propuesta de política del derecho en materia de sucesiones por causa de muerte", en APDC. Derecho de sucesiones. Presente y futuro. XIIJornadas de la Asociación de Profesores de Derecho civil. Murcia: Servicio de Publicaciones de la Universidad de Murcia.

Domínguez, Ramón y Ramón Domínguez (2011). Derecho sucesorio. Santiago: Editorial Jurídica de Chile, vol. II.

Eekelaar, John (1993). "Are Parents Morally Obliged to Care for their Children?", in John EekelaAR \& Petar ŠArčEvić (eds.). Parenthood in Modern Society. Legal and Social Issues for the Twenty-First Century. Dordrecht/Boston/London: Martinus Nijhoff Publishers.

Elorriaga, Fabián (1995). Régimen jurídico de la vivienda familiar. Navarra: Editorial Aranzadi.

Elorriaga, Fabián (2015). Derecho sucesorio. $3^{\mathrm{a}}$ ed. Santiago: Editorial AbeledoPerrot.

Elorriaga, Fabián (2019). "La libertad de testar y sus restricciones. Consideracio-

136 nes para su eventual revisión en Chile”, en Manuel BARRIA, José Luis DíEz, Iñigo DE la Maza, Rodrigo Momberg, Gonzalo Montory y Álvaro Vidal (dirs. y coords.). Estudios de derecho privado en homenaje a Daniel Peñailillo Arévalo. Santiago: Editorial Thomson Reuters.

EsPadA, Susana (2007). Los derechos sucesorios de las parejas de hecho. Madrid: Editorial Thomson-Civitas.

FACAL, Teresa y M. del Pilar Torréns (2010). "Cambios sociológicos en la familia con repercusión en el Derecho de sucesiones", en Ángel Luis Rebolledo (coord.). La familia en el derecho de sucesiones: cuestiones actuales y perspectivas de futuro. Madrid: Editorial Dykinson.

García, M. Paz, M. Isabel Louro, Xaime M. Requeixo, Antonia Nieto, Margarita Herrero, Marta Otero, Carolina Mesa y Juan P. Pérez (2017). "Los testamentos de las mujeres", en Teodora Torres (dir.). Construyendo igualdad: la feminización del derecho privado. Valencia: Editorial Tirant lo Blanch.

Instituto Nacional de Estadísticas (2017). Presentación de la Segunda entrega de resultados censo 2017. Disponible en www.censo2017.cl/wp-content/uploads/ 2018/05/presentacion_de_la_segunda_entrega_de_resultados_censo2017.pdf [fecha de consulta: 24 de agosto de 2020].

InSTITUTO NACIONAL DE EsTADÍSTICAS (2018). Estimaciones y proyecciones de la población en Chile 1992-2050. Síntesis de Resultados del Instituto Nacional de Estadísticas (INE). Disponible en www.censo2017.cl/descargas/proyecciones/sintesisestimaciones-y-proyecciones-de-la-poblacion-chile-1992-2050.pdf [fecha de consulta: 24 de agosto de 2020]. 
LaCruZ, José Luis (2004). Elementos de derecho civil V. Sucesiones. Madrid: Editorial Dykinson.

Lepín, Cristián (2014). "Los nuevos principios del Derecho de Familia". Revista Chilena de Derecho Privado, n. ${ }^{\circ}$ 23. Santiago.

LóPEZ, Ángel Manuel (1994). "La garantía institucional de la herencia". Derecho Privado y Constitución, n. ${ }^{\circ}$ 3. Madrid.

Magariños, Victorio (2005). "La libertad de testar". Revista de Derecho Privado, año 89, n. $^{\circ}$ 5. Madrid.

Malaurie, Philippe et Claude Brenner (2018). Droit des successions et des liberalités. Paris: LGDJ.

MiQuel, José María (2002). "Notas sobre 'la voluntad del testador”. Revista Jurídica de la Universidad Autónoma de Madrid, n. ${ }^{\circ}$ 6. Madrid.

Moreu, José Luis (1997). “Aportación a la doctrina sobre la legítima aragonesa en contemplación a su futura reforma legal". Anuario de Derecho Civil, n. ${ }^{\circ}$. Madrid.

NAvas, Susana (2011). "Freedom of Testation versus Freedom to enter into succession agreements and transaction costs", in Esther Arroyo \& Miriam ANDERSON (eds.). The Law of Succession: Testamentary Freedom. European perspectives. Groningen: European Law Publishing.

Pantaleón, Fernando (2003). "Legítimas de alimentos". Escritura Pública, n. 21. Madrid.

PARRA, M. Ángeles (2009). "Legítimas, libertad de testar y transmisión de un patrimonio". Anuario da Facultade de Dereito da Universidade da Coruña, n. ${ }^{\circ} 13$. La Coruña.

Pintens, Walter (2011). "Need and Opportunity of Convergence in European Succession Laws", in Esther Arroyo \& Miriam Anderson (eds.). The Law of Succession: Testamentary Freedom. European perspectives. Groningen: Europa Law Plublishing.

Rebolledo, Ángel Luis (2010). "La actualización del Derecho sucesorio español ante los cambios sociológicos y jurídicos de la familia: conclusiones de una investigación”, en Ángel Luis Rebolledo (coord.). La familia en el Derecho de sucesiones: cuestiones actuales y perspectivas de futuro. Madrid: Editorial Dykinson.

Roca, Encarna (2014). Libertad y familia. Valencia: Editorial Tirant lo Blanch.

Rodríguez, Pablo (2002). Instituciones de derecho sucesorio. Santiago: Editorial Jurídica de Chile, vol. I.

Rodríguez, M. Sara (2010). "Contracción de las asignaciones forzosas. Una reforma urgente del sistema sucesorio chileno", en Departamento de Derecho Privado Universidad de Concepción (coord.). Estudios de derecho civil $V$. Santiago: Editorial Abeledo Perrot.

Rodríguez, M. Sara (2019). "Derogar la cuarta de mejoras". El Mercurio Legal, 6 de mayo 2019. Disponible en www.elmercurio.com/legal/noticias/analisisjuridico/2019/05/06/derogar-la-cuarta-de-mejoras.aspx [fecha de consulta: 24 de agosto de 2020]. 
Röthel, Anne (2008). El derecho de sucesiones y la legítima en el derecho alemán. Barcelona: Editorial Bosch.

SAlah, M. Agnes (2019). "Tres visiones de la igualdad para el Derecho sucesorio", en Esteban Pereira (ed.). Fundamentos filosóficos del derecho chileno. Santiago: Rubicón Editores.

SENADIS (2016). Presentación de la Resultados "II Estudio Nacional de la Discapacidad. Un nuevo enfoque para la inclusión”. Disponible en www.senadis.gob. cl/pag/306/1570/publicaciones [fecha de consulta: 24 de agosto de 2020].

SERnA, Encarna (2010). "Los derechos sucesorios de los hijos de los nuevos modelos familiares", en Ángel Luis Rebolledo (coord.). La familia en el derecho de sucesiones: cuestiones actuales y perspectivas de futuro. Madrid: Editorial Dykinson.

Servicio de Registro Civil e Identificación (2017). Datos registrales con enfoque de género. Programa Equidad de Género 2017. Disponible en www.registrocivil.cl/ PortalOI/transparencia/DatoInteresCiudadano/Datos_Registrales_por_Genero_2017_1.pdf [fecha de consulta: 24 de agosto de 2020].

Torres, Teodora (2006). "Legítima, legitimarios y libertad de testar (síntesis de un sistema)", en APDC. Derecho de sucesiones. Presente y futuro. XIIJornadas de la Asociación de Profesores de Derecho civil. Murcia: Servicio de Publicaciones de la Universidad de Murcia.

Torres, Teodora y M. Paz García (2014). La libertad de testar: el principio de igualdad, la dignidad de la persona y el libre desarrollo de la personalidad en el derecho de sucesiones. Madrid: Fundación Coloquio Jurídico Europeo.

VAQUER, Antonio (2007). "Reflexiones sobre una eventual reforma de la legítima". Indret, $\mathrm{n} .^{\circ}$ 3. Barcelona.

VAQUER, Antonio (2017). "Acerca del fundamento de la legítima”. Indret, n. ${ }^{\circ} 4$. Barcelona.

WALKer, Nathalie (2019): "El anacronismo de las asignaciones forzosas y el necesario reconocimiento de la libertad de testar", en Esteban PEREIRA (ed.). Fundamentos filosóficos del derecho chileno. Santiago: Rubicón Editores.

\section{Normas citadas}

Code francés de 1804.

Código Civil austriaco (ABGB).

Código Civil.

Código Civil colombiano.

Código Civil de Luisiana.

Código Civil español.

Código Civil y Comercial de la Nación argentina.

Constitución Política de la República. 
Ley n. ${ }^{\circ} 21150$, que modifica la Ley n. 20530 y crea el Ministerio de Desarrollo Social y Familia. Diario Oficial de la República de Chile, Santiago, 16 de abril de 2019.

Ley n. ${ }^{\circ} 1934$, por medio de la cual se reforma y adiciona el Código Civil. Diario Oficial de la República de Chile, Santiago, 2 de agosto de 2018.

Ley 41/2003, de protección patrimonial de las personas con discapacidad y de modificación del Código Civil, de la Ley de Enjuiciamiento Civil y de la Normativa Tributaria con esta finalidad. BOE, Madrid, 19 de noviembre de 2003.

Proyecto que fortalece la libertad de testar eliminando la cuarta de mejoras. Boletín n. ${ }^{\circ}$ 12.301-07, Santiago, 11 de diciembre de 2018.

\section{Jurisprudencia citada}

Tribunal Constitucional Federal alemán, 19 de abril de 2005, en NJW, vol. 58, n²2. Múnich.

\section{SigLAS Y ABREVIATURAS}

ABGB Allgemeines bürgerliches Gesetzbuch

$$
\text { al. alii (otros) }
$$

APDC Asociación de Profesores de Derecho civil

art. artículo

arts. artículos

BOE Boletín Oficial del Estado

CC Código Civil

coords. coordinadores

CPR Constitución Política de la República

dirs. directores

ed. editor $a$ veces edición

eds. editores

https HyperText Transfer Protocol Secure

inc. inciso

INE Instituto Nacional de Estadísticas

LGDJ Libraire Generale de Droit Juris

n. ${ }^{\circ}$ a veces $\mathrm{N} .^{\circ}$ número

NJW Neue Juristische Wochenschrift

op. cit. opere citato (obra citada)

p. página

PeSD personas en situación de discapacidad 
0
$\frac{1}{2}$
$\frac{1}{U}$
0
0
0
0
0
$\frac{0}{3}$
$\frac{U}{2}$
$\frac{1}{4}$

$\begin{aligned} \text { pp. } & \text { páginas } \\ \text { SENADIS } & \begin{array}{l}\text { Servicio Nacional de la Discapaci- } \\ \text { dad }\end{array}\end{aligned}$

ss. siguientes

vol. volumen

www World Wide Web 